laser crystals. M. Genet et al. (Institut de Physique Nucléaire, Orsay) described a $\mathrm{ThBr}_{4}$ phosphor, efficient as a scintillator and capable of excitation by a $\beta$ source to give enough light to a photovoltaic cell to provide an energy convertor of about $0.3 \%$ efficiency! To these we may add recent phosphors, reviewed by A. L. N. Stevels (Philips Research Laboratories, Eindhoven) which may be used to give three component fluorescent lamps, substitutions for the sulphide phosphors of cathode ray tubes and for the current X-ray intensifying screens. All of these materials utilise the features of rare earth activators in a variety of host crystals.

Among new effects reported at the meeting, E. Nakazawa (NHK Broadcasting Science Research Laboratories, Tokyo) described photon absorption and emission at twice the energy of the individual level separations of cooperating pairs of rare earth ions in an yttrium phosphate crystal. One might ask, what has happened to the former extensive interest in electroluminescence? There were some papers on the subject at the meeting but lack of financial largesse has forced research into a narrower range of materials, notably into studies of the deep lying band gap states in GaP, GaAs and their alloys and into other features which might be holding down the efficiency of light-emitting diodes. This basic work seems preferable to free ranging over every possible electroluminescent system although there is still an unsatisfied hope of a breakthrough in high band gap crystals like $\mathrm{ZnS}$ and $\mathrm{ZnSe}$.

The institution of informal discussion groups on specific topics, such as picosecond techniques, proved very popular. Organisation in all respects was excellent and set a high standard for emulation at the next conference to be held in Paris in 1978 .

\section{Neutron diffraction in Holland}

from G. E. Bacon

A meeting on New Methods and Techniques in Neutron Diff raction was held on August 5-6 at the Reactor Centrum Nederland near Amsterdam. Papers presented at the meeting will be published as a report of the Reactor Centrum Nederland.

AFTER attending international meetings on neutron diffraction for a quarter of a century it was a new experience to go to one at which only 8 , out of an audience of 127 , came from the United States. At first sight such a circumstance at the Reactor Centrum Nederland at Petten, near Amsterdam, may be thought simply to underline the increasing financial difficulties which face those who have to travel large distances to keep in touch with their scientific colleagues. More fundamentally the unusual ratio reffected the dividend which is now being paid for the Franco-German, and latterly and more tardily the British, collaboration in the High Flux Beam Reactor at the Institut Laue-Langevin in Grenoble. More specifically, much of the discussion at this meeting reflected the success of the German investment in guide tubes and other neutron optical devices inspired by $\mathbf{H}$. Maier-Leibnitz. The papers were restricted to topics relating to elastic scattering only.

The six sessions made it clear that the number of available techniques in this field is immensely larger than it was 5 or 10 years ago, mainly because a high flux makes a practical possibility of many methods which developments in computing had made possible, in principle, some years earlier. The employment of position-sensitive detectors, contrast-variation in small-angle scattering by biological substances, polarisation analysis and powder-profile refinement are now producing scientific results concerning interesting materials, rather than demonstration experiments. For example, in protein molecules, by labelling different parts of the molecule with selective deuteration, it is possible to do much more than determine an average radius of gyration. By smallangle scattering also (G. Lippmann, Institut für Festkörperforschung der Kernforschungsanlage, Julich, BDR) the dimensions of the nickel-depleted zones in invar alloys have been found. By profile-refinement, structures have been determined (J. C. Taylor, Chemical Physics Division, Lucas Heights, Australia) for a wide range of uranium compounds which are very intractable for growing and maintaining as single crystals. D. Hohlwein (Institut LaueLangevin, Grenoble) indicated the practical possibilities of photographic detection, showing, for example, neutron Weissenberg photographs of the superstructure reflections from the mineral labradorite. M. Schlenker (Laboratoire du Magnetisme, CNR, Grenoble) showed how the penetrating ability of neutrons enabled topographic studies to be extended to the interior of crystals, thus effectively studying a section through a crystal without the disadvantage of having to destroy it by cutting a slice.

Rather belatedly perhaps, work has thrived on the use of pulsed sources, including particle-accelerating machines, for neutron diffraction experi- ments using time-of-flight techniques. This is not solely because of the advantages which the fixed geometry yields for the production of cryostats, furnaces and high-pressure cells but probably with an eye to the future, where the next generation of neutron sources may well not be the conventional reactor, but some kind of neutron booster or spallation machine capable of increasing neutron beam intensities by another order of magnitude.

\section{From babble to Babel}

\author{
by Miranda Robertson
}

The Third International Child Language Symposium was held in London on September 3-5.

It was linguistic theory, and in particular the transformational grammar of Noam Chomsky, that led to the recent surge of interest in child language; but while the interest is unabated, it seems that the influence of linguistics has begun to wane. Chomsky's view that the deep structures of his transformational grammar reflect the innate organisation of the neural substrates for language led researchers to look for evidence in the earliest utterances of infants and in fundamental similaritics in the first sentences of children speaking widely different tongues. It is now generally felt however that transformational grammar has failed to illuminate either.

Richard Cromer (MRC Child Development Unit, London), as chairman of the session on the acquisition of syntax, attempted to categorise the advances and retreats. For example, as he pointed out, there is less work on syntax but more on semantics. That is partly because of a belated realisation that it is impossible to separate the two, since in order to look at how a child starts to use syntax to express his meaning it is necessary to know what meaning he intended to express. And it is the need to understand the child's semantic intentions that has led to another important reorientation (or in Cromer's terms, an advance)-from the dogmatic to the pragmatic approach. That has led to the use of the ethological research strategy promulgated perhaps most notably by Professor Jerome Bruner (Oxford University).

What, then, have psycholinguists learned by watching the emergence of infant speech in its natural habitat? Elizabeth Bates and her colleagues (University of Rome) have been able to follow the progression from gesture to first word in a longitudinal study on Italian children from the age of 2 